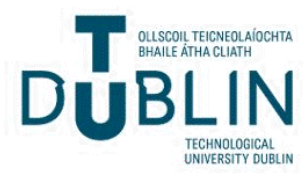

Technological University Dublin ARROW@TU Dublin

2015-05-18

\section{Insole Antenna for On-Body Telemetry}

Domenico Gaetano

Dublin Institute of Technology, domenico.gaetano@mydit.ie

Patrick McEvoy

Technological University Dublin, patrick.mcevoy@tudublin.ie

Max Ammann

Technological University Dublin, max.ammann@tudublin.ie

See next page for additional authors

Follow this and additional works at: https://arrow.tudublin.ie/engscheleart2

Part of the Electromagnetics and Photonics Commons, and the Equipment and Supplies Commons

\section{Recommended Citation}

Gaetano, D.; McEvoy, P.; Ammann, M.J.; John, M.; Brannigan, C.; Keating, L.; Horgan, F. (2015) Insole Antenna for On-Body Telemetry. IEEE Transactions on Antennas and Propagation, vol. 63, no. 8, pp. 3354-3361. doi:10.21427/D7S884

This Article is brought to you for free and open access by the School of Electrical and Electronic Engineering at ARROW@TU Dublin. It has been accepted for inclusion in Articles by an authorized administrator of ARROW@TU

Dublin. For more information, please contact

arrow.admin@tudublin.ie, aisling.coyne@tudublin.ie, gerard.connolly@tudublin.ie. Funder: Science Foundation Ireland 


\section{Authors}

Domenico Gaetano, Patrick McEvoy, Max Ammann, Matthias John, Colm Brannigan, Louise Keating, and Frances Horgan 


\title{
Insole Antenna for On-Body Telemetry
}

\author{
D. Gaetano, P. McEvoy, Senior Member, IEEE, M. J. Ammann, Senior Member, IEEE, \\ M. John, Member, IEEE, C. Brannigan, L. Keating, F. Horgan
}

\begin{abstract}
A $433 \mathrm{MHz}$ antenna is proposed for integration with the insole of footwear for a body area network. The folded dipole design with an asymmetric groundplane radiates from its edges and considers the close proximity of the human foot and ground surfaces. It functions for different ground conductivity conditions and an on-body communication link with an Inverted-F Antenna in the upper body area was evaluated on a static and dynamic human subject. The antenna solution was compliant with Specific Absorption Rate requirements, remains matched and links with upper-body nodes regardless of the body posture and node location.
\end{abstract}

Index Terms - Footwear antenna, Body Area Network, ISM $433 \mathrm{MHz}$, Propagation Channel

\section{INTRODUCTION}

Emerging opportunities for wearable electronics include sensors for footwear [1-3] and associated communications [4] to enable medical [5], occupational [6] and leisure [7] applications. The volume and rigidity of footwear can contain low-profile and conformal components without undue impact on the flexibility of a subject's foot or natural gait. Without awkward wires, wireless footwear nodes will link with upper-body, off-body or combinations of on/offbody nodes [8], including full-fabric antennas [9]. Lower wavelength antennas offer increased propagation range. Larger dimensions support better radiation efficiencies and footwear can comfortably accommodate larger antennas that would otherwise be more noticeable higher up the body.

Integrated ergonomic footwear antennas will have to support sustainable radio channels in electromagnetic environments with various material loads due to human tissues, footwear and ground surfaces with varying proximities and that may have high water content $[10,11]$. Additionally, footwear nodes are furthest from upper body nodes and their relative positions can change rapidly during leg movement with associated variations in path loss. Resilient devices require mechanical stability and protection from scuffing that occurs on outer surfaces.

Manuscript received September 02, 2014; revised February 26, 2015; accepted May 10, 2015. Date of publication XX XX, XXX; date of current version XX XX, XXXX. This work was supported by Science Foundation Ireland grants: 09/IN.1/I2652, 13/TIDA/I2746 and 10/CE/I1853.

D. Gaetano, P. McEvoy and M. J. Ammann are with the Antenna and High Frequency Research Centre, School of Electrical and Electronic Engineering, Dublin Institute of Technology, Ireland (e-mail: ammann@ieee.org).

M. John is with CTVR - the Telecommunication Research Centre, Trinity College Dublin, Dublin 2, Ireland (e-mail: johnm@tcd.ie).

L. Keating, C. Brannigan and F. Horgan are with the School of Physiotherapy, Royal College of Surgeons in Ireland, Dublin 2, Ireland (e-mail: fhorgan@rcsi.ie).
A $2.3-2.65 \mathrm{GHz}$ wireless pedometer, using a printed inverted-F antenna with parasitic elements, was reported with basic measurements for integration between the footwear insole and sole [12]. An RFID tag in the form of a commercial brand logo used a $433 \mathrm{MHz}$ dipole on the external sides of a sports shoe [13]. The simulated radiating pattern and the measured matched impedance varied notably with/without the foot. Similarly, a $900 \mathrm{MHz} / 2.4 \mathrm{GHz}$ dualband monopole, shaped as another brand logo and fed with a $50 \Omega$ microstrip line, had a limited range [14].

Alternatively, short-range radar detection of buried anti-personnel mines using a shoe toe-cap was proposed with a single-sided CPW-fed $1.7 \mathrm{GHz} / 2.9 \mathrm{GHz}$ dual-band bow-tie slot antenna printed on $0.9 \mathrm{~mm}$ thick leather [15].

Ultra Wideband (UWB) performances for a monopole antenna and a Vivaldi antenna printed on $0.2 \mathrm{~mm}$ thick FR4 were reported for footwear toe-cap, heel counter (rear) and lateral-quarter (side) positions [10]. E-field plots illustrated the performance for several full-body postures and the ground surface influence for the heel-mounted Vivaldi.

The first reported channel link-reliability for footwear to upper body nodes demonstrated the need to consider system performance [4]. In addition, a 2.4-11.0 GHz spline-shaped monopole antenna printed on $0.2 \mathrm{~mm}$ flexible FR4 assessed toe-cap to wrist nodes links [16]. While ground proximities influences were excluded, the path-loss measurements for indoor walking scenarios fitted a Rician channel distribution.

Compared with higher frequencies, the $69 \mathrm{~cm}$ wavelength of the ISM $433 \mathrm{MHz}$ channel offers lower propagation loss and an improved link budget. In proximity with human tissue, it offers reasonable off-body link range and channel resilience to variations in posture, physiology and ground conductivity. However, for on-body links at sub-GHz frequencies, shadowing effects due to body movement were reported as dominant over multipath fading [17].

Upper body antenna designs tend to be narrowband due to restricted dimensions [18-22]. Furthermore, the impact of tissue loading on the reflection coefficient in dipoles [23], loops, helix antennas [18, 22], patch antennas [19] were reported without link analyses to other body area antennas. While static posture on-body antenna links have been reported [20, 21], dynamic systems are under-reported.

A large $433 \mathrm{MHz}$ antenna is proposed to be inserted between a footwear sole and insole. Printed on single-sided $0.2 \mathrm{~mm}$ FR4, it radiated along the lateral edges to minimize loss into the foot. Matched impedance modeling for different ground surface conductivities and propagation links with upper body areas were validated using indoor measurements of subjects in static and dynamic postures. Specific absorption rate was also modeled. 


\section{ANTENNA}

\section{A. Antenna Design}

In order to maximize link performances, while avoiding discomfort or distraction to the subject, a larger antenna was integrated under a footwear insole. Insole antennas would easily fit within different types of footwear, along with various biometric sensors. The system should function despite loading by human foot tissues and ground surfaces with different electrical properties, or as the foot lifts up into quasi freespace conditions. In this case, the $2 \mathrm{~mm}$ thick insole was $275 \mathrm{~mm}$ long and varied from $60 \mathrm{~mm}$ to $90 \mathrm{~mm}$ in width. The footwear sole underneath was $25 \mathrm{~mm}$ thick. CST Microwave Studio was used to simulate the electromagnetic environment. The simulated heterogeneous anatomical foot and shoe model is shown in Fig. 1, with material properties listed in Table I [24].

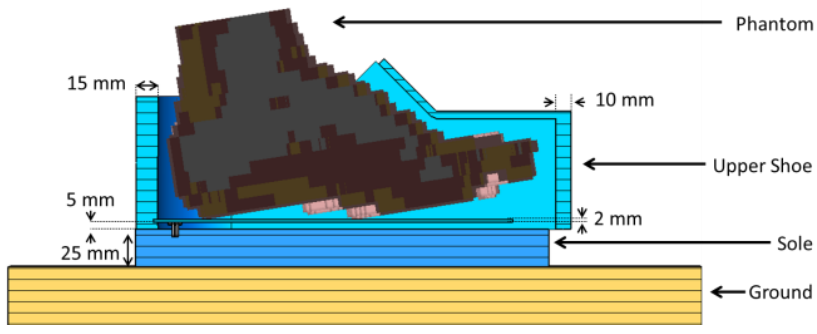

Fig. 1. CST model of antenna under heterogeneous voxel foot in shoe over reinforced concrete ground

TABLE I

ELECTRICAL PROPERTIES OF BODY, SHOE MATERIAL AND GROUND

\begin{tabular}{|l|c|c|c|}
\hline & $\boldsymbol{\varepsilon}^{\prime}$ & $\boldsymbol{\sigma}$ & $\tan \boldsymbol{\delta}$ \\
\hline Muscle & 56.88 & 0.80 & - \\
\hline Skin & 46.10 & 0.70 & - \\
\hline Fat & 5.57 & 0.04 & - \\
\hline Bone & 13.10 & 0.09 & - \\
\hline Upper Shoe & 1.4 & - & 0.04 \\
\hline Sole & 3.0 & - & 0.06 \\
\hline Reinforced Concrete & 6.0 & 0.00195 & - \\
\hline PEC & - & $\infty$ & - \\
\hline
\end{tabular}

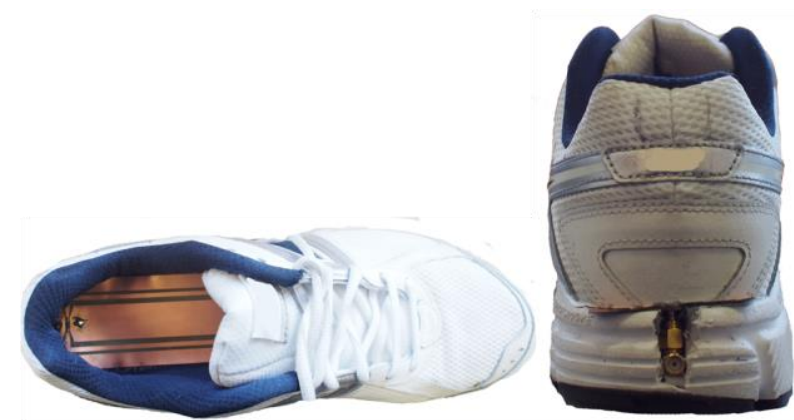

Fig. 2. Antenna inserted without insole cover.

Fig. 2 shows the prototype antenna installed in the shoe without the insole overlay. It was inserted through a horizontal slot between the heel and the upper area, with the connector accommodated in a cavity in the sole.

A $0.2 \mathrm{~mm}$ thick single sided FR4 substrate was used for the antenna, shown in Fig. 3. The unbalanced feed drives a folded dipole antenna with a ground plane at the edges and within the folded element. The coplanar waveguide feed was stimulated with an SMA connector from under the dielectric; with a CPW transition required due to the proximity of the connector flange.
The antenna was optimized using CST's Trust Region Framework algorithm. The input impedance was refined by allowing groundplane length to vary, $90 \leq G P_{2} \leq 150 \mathrm{~mm}$. The matched impedance bandwidth was varied with $\mathrm{S}_{5}$ and the longer length $L$ lowered the resonance frequency. The overall dimensions of the antenna were $243 \mathrm{~mm} \times 51 \mathrm{~mm}$, summarised in Table II. While the dimensions were critical to the resonance bandwidth, they established insensitivity to variations due to material loading.

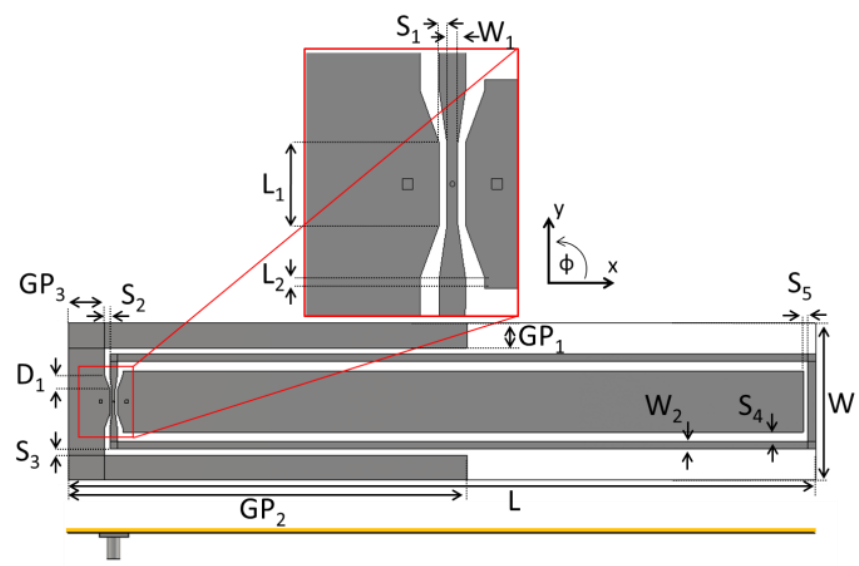

Fig. 3. Geometry of the antenna

TABLE II

INSOLE ANTENNA DIMENSIONS

\begin{tabular}{|c|c|c|c|}
\hline Parameter & $\begin{array}{c}\text { Dimension } \\
{[\mathbf{m m}]}\end{array}$ & Parameter & $\begin{array}{c}\text { Dimension } \\
{[\mathbf{m m}]}\end{array}$ \\
\hline$W$ & 51.0 & $S_{5}$ & 1.50 \\
\hline$L$ & 243.61 & $G P_{1}$ & 8.00 \\
\hline$W_{1}$ & 1.04 & $G P_{2}$ & 130.00 \\
\hline$W_{2}$ & 2.50 & $G P_{3}$ & 11.75 \\
\hline$S_{l}$ & 0.73 & $L_{l}$ & 7.87 \\
\hline$S_{2}$ & 1.83 & $L_{l}$ & 1.00 \\
\hline$S_{3}$ & 2.00 & $D_{1}$ & 5.00 \\
\hline$S_{4}$ & 3.12 & \multicolumn{3}{|}{} \\
\hline
\end{tabular}

\section{B. Antenna Performance}

Indoor ground surfaces include concrete or timber, often covered with various low permittivity materials. For outdoors, permittivity can range from $5 \leq \varepsilon_{\mathrm{r}} \leq 100$ and conductivity from $10^{-4} \leq \sigma \leq 1 \mathrm{~S} / \mathrm{m}$ [25]. While walking or running, the foot can lift off the ground into semi-freespace. Sample underfoot conditions were simulated for freespace, reinforced concrete [26] and Perfect Electrical Conductor (PEC), where PEC represents high conductivity associated with a running treadmill or bridge structure. The antenna performance was optimized for proximity with ground surfaces but with resilience to foot lift conditions.

The antenna was designed to radiate from the edges and the current distribution was dominant on the outer layers of the ground plane and on the transmission line, with small concentration at the centre ground plane, as shown in Fig. 4. This is due to the asymmetric groundplane dimensions, $\mathrm{S}_{3}$ and $\mathrm{S}_{4}$ which control the coupling with the external groundplane.

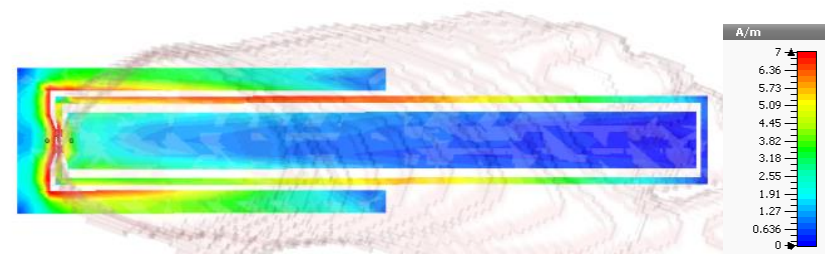

Fig. 4. Maximum amplitude of the current at $433 \mathrm{MHz}$. 
Simulated and measured $S_{11}$ data for the freespace case and for the foot-shoe model with different types of ground are shown in Fig. 5.

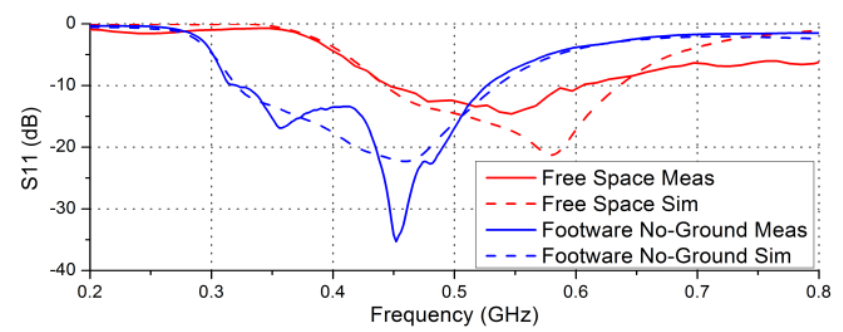

(a)

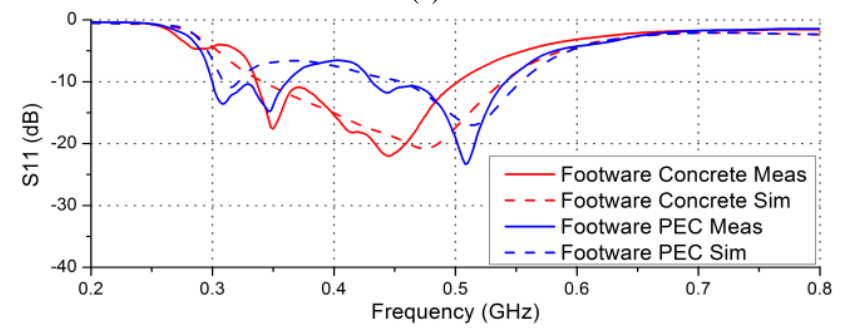

(b)

Fig. 5. Simulated and measured $S_{11}$ for (a) freespace and in a shoe in freespace, (b) in a shoe over reinforced concrete and PEC.

The correlation between the simulated and measured data validates the static model. Table III summarizes the matched impedance bandwidth results for $S_{11(-6 \mathrm{~dB})}$ and $S_{11(-10 \mathrm{~dB})}$.

Differences between simulated and measured values of the lower edge frequencies were attributed to proximity variations between the foot anatomy and the antenna and discrepancies between the foot anatomical model and the actual electrical properties in the measured environment.

TABLE III

COMPARISON BETWEEN SIMULATED AND MEASURED ON-BODY DATA

\begin{tabular}{|l|c|c|c|c|c|}
\hline \multicolumn{2}{|c|}{} & \multicolumn{2}{c|}{ Simulated [MHz] } & \multicolumn{2}{c|}{ Measured [MHz] } \\
\cline { 3 - 6 } \multicolumn{2}{|c|}{} & $f_{\text {low }}$ & $f_{\text {high }}$ & $f_{\text {low }}$ & $f_{\text {high }}$ \\
\hline \multirow{3}{*}{ Freespace } & $-10 \mathrm{~dB}$ & 443 & 634 & 448 & 607 \\
\cline { 2 - 6 } & $-6 \mathrm{~dB}$ & 418 & 668 & 413 & 697 \\
\hline $\begin{array}{l}\text { No } \\
\text { Ground }\end{array}$ & $-10 \mathrm{~dB}$ & 319 & 534 & 322 & 526 \\
\cline { 2 - 6 } $\begin{array}{l}\text { Reinforced } \\
\text { Concrete }\end{array}$ & $-6 \mathrm{~dB}$ & 306 & 570 & 306 & 564 \\
\hline \multirow{3}{*}{\begin{tabular}{l} 
PEC \\
\cline { 2 - 6 }
\end{tabular}} & $-10 \mathrm{~dB}$ & 341 & 539 & 336 & 502 \\
\cline { 2 - 6 } & $-10 \mathrm{~dB}$ & 310 & 574 & 328 & 540 \\
\cline { 2 - 6 } & $-10 \mathrm{~dB}$ & 308 & 322 & 300 & 360 \\
\cline { 2 - 6 } & $-6 \mathrm{~dB}$ & 298 & 582 & 294 & 568 \\
\hline
\end{tabular}

Both simulations and measurements met requirements for the ISM $433 \mathrm{MHz}$ bandwidth at $-6 \mathrm{~dB}$ and $-10 \mathrm{~dB}$. The $-10 \mathrm{~dB}$ measured fractional bandwidth for the footwear No Ground case was 48\%. Standing on Reinforced Concrete, the bandwidth reduced to $39 \%$ and to $22 \%$ for standing on PEC. The PEC degrades the $\mathrm{S}_{11 \text { (-10dB) }}$ mid-band. It is anticipated that for outdoor conditions where the footwear is partially immersed in water, the radiating fields would attenuate in the lossy material.

\section{Evaluation of Specific Absorption Ratio (SAR)}

A Specific Absorption Rate (SAR) calculation was used to assess electromagnetic deposition in the foot. The European Union [27] and United States [28] limits for local peak SAR in limb extremities is $4 \mathrm{~W} / \mathrm{Kg}$ averaged over $10 \mathrm{~g}$, normalized to a $1 \mathrm{~W}$ input power. The SAR was simulated using the anatomical voxel foot over the three ground scenarios. The antenna was $25 \mathrm{~mm}$ over the ground due to the footwear sole thickness. At the closest point, the antenna was $2 \mathrm{~mm}$ from the voxel model, offset by the thickness of insole, with greater gaps near the foot arch and toes. The SAR distributions over different grounds are shown in Fig. 6, with maximum values in Table IV.
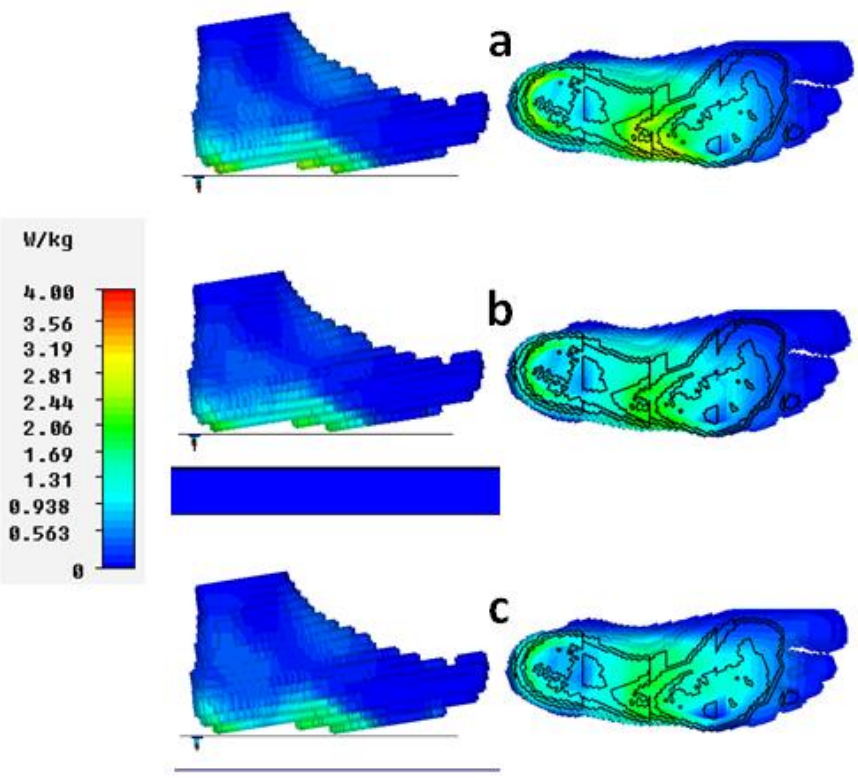

Fig. 6. Simulated foot SAR: (a) no ground, (b) reinforced concrete, (c) PEC.

TABLE IV

\begin{tabular}{|c|c|}
$433 \mathrm{MHz}$ SIMULATED SAR $(10 \mathrm{~g}[\mathrm{~W} / \mathrm{KG}])$ \\
\hline No Ground & 2.55 \\
\hline Reinforced Concrete & 2.08 \\
\hline PEC & 1.87 \\
\hline
\end{tabular}

In general, the SAR was greater in the foot sole where the lateral quarter was closest to the radiating element and near the feed point under the heel. The peak SAR position and pattern was consistent for the different grounds types. The lower value of SAR in the presence of the ground was due to a greater power absorption in the shoe sole.

\section{ON-BODY COMMUNICATION LINK}

\section{A. Measurement Setup}

The performance of the transmission link from the $433 \mathrm{MHz}$ insole antenna to the upper body nodes was investigated with $S_{21}$ measurements with a smaller antenna. The small antenna was designed for a perpendicular polarization to minimize coupling with the body and to enable equivalent comparisons between 14 different on-body positions to represent complete coverage, as shown in Fig. 7: Front Head; Left and Right Upper Arm; Left, Right, Front Upper Chest; Cervical Spine; Front Chest; Lumbar Spine; Left, Right and Front Waist; Left and Right Upper Leg.

It is envisaged that this work will inform design strategies for more ergonomic and proprietary antennas for the upper body nodes at positions that correspond with potential on-body sensors. Measurements were performed for a stationary subject with the arms hanging alongside the torso and for a walking subject. 


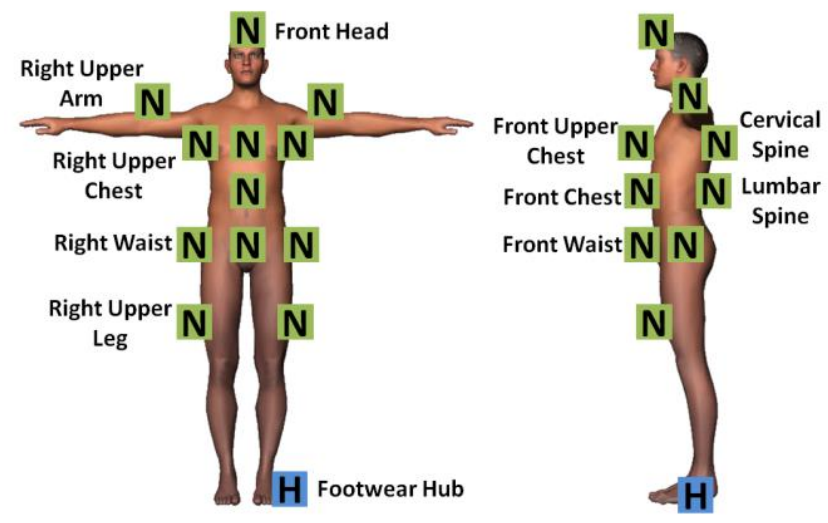

Fig. 7. Hubs and nodes positions for $\mathrm{S}_{21}$ measurements.

\section{B. Design of receiving antenna}

The small $433 \mathrm{MHz}$ Inverted $\mathrm{F}$ antenna designed for the upper-body is shown, unfolded, in Fig. 8. The antenna substrate was Taconic RF-35 $\left(\varepsilon_{\mathrm{r}}=3.5, \tan \delta=0.0018\right)$ with a thickness of $6.2 \mathrm{~mm}$. The ground plane was on $0.2 \mathrm{~mm}$ FR4 substrate to stabilise mounting on the upper body surface. The overall dimensions without the ground plane were $70 \times 25 \mathrm{~mm}^{2}$. The matching impedance was controlled with the position of a transmission line than short circuit the feed to the ground. To cover the $433 \mathrm{MHz}$ frequency, the edge metal strip was side-fed and wrapped onto the substrate top edge and opposite side edge. The final fold was onto the front face. An SMA connector was used to feed the antenna without any balun. The groundplane dimensions, $70 \times 60 \mathrm{~mm}^{2}$ were a trade-off between maximising the groundplane and minimizing body coupling with the antenna.

The antenna dimensions were optimized when located on the front waist of the Gustav voxel model. The antenna was smaller than $\lambda_{0} / 9$. The antenna was oriented perpendicular to the body surface to ensure a perpendicular polarization with respect to the body positions [29], as shown in Fig. 9. The antenna polarization was chosen to excite surface waves with capacity to creep around the body surface and overcome some of the body shadowing effects [30].

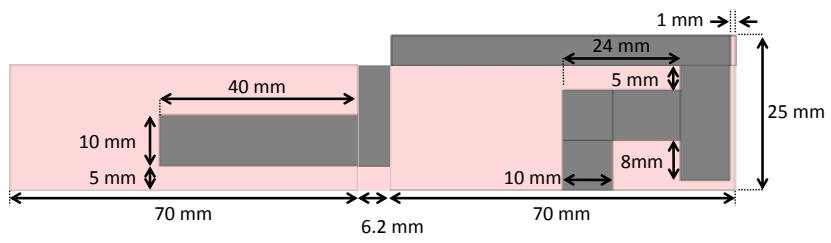

Fig. 8. Extended geometry with dimension of the $433 \mathrm{MHz}$ antenna.

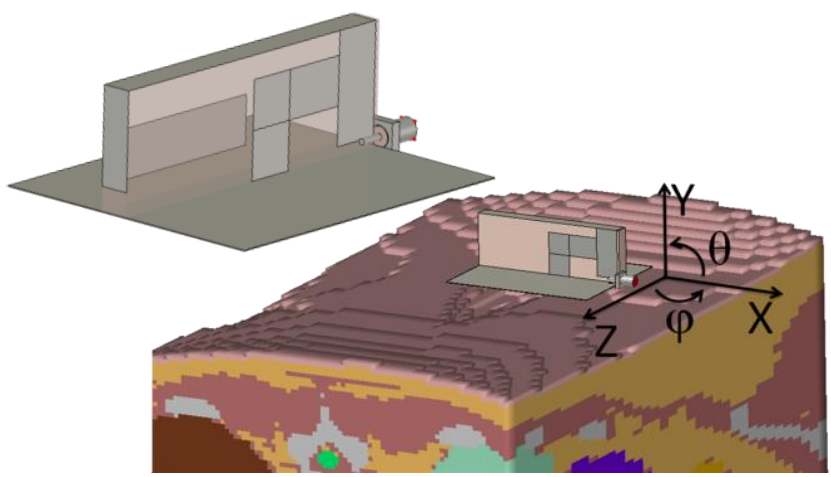

Fig. 9. $433 \mathrm{MHz}$ node antenna, (a) in 3D, and (b) on the front of the waist
For the upper arm positions, where the dielectric load was lower than the other locations, the resonant frequency was higher. The $\mathrm{S}_{11}$ minimum was within the $426 \mathrm{MHz}$ and $450 \mathrm{MHz}$ frequency range. In all the measured locations, the small antenna $S_{11}$ was better than $-7.8 \mathrm{~dB}$. Discrepancies in frequencies between $433 \mathrm{MHz}$ and minimum $\mathrm{S}_{11}$ were always less than $17 \mathrm{MHz}$.

The impact on antenna performance by the body was minimized by the groundplane. The simulated radiation pattern was omnidirectional, when the antenna was located on the body, with a maximum realized gain of $-6 \mathrm{dBi}$.

\section{On-Body measurements for immobile subject}

With the lower frequency over short distances, the antenna near field links can prevail. Instead of radiation patterns, performances were assessed with $S_{21}$ measurements to a probe antenna. $S_{21}$ measurements of footwear links with the 14 upper-body nodes were performed on a subject $(70 \mathrm{~kg}$, $1.75 \mathrm{~m}$ tall). The immobile subject was in a laboratory, $8.1 \times 7.9 \mathrm{~m}^{2}$ area, with metallic furniture and reinforced concrete in the floor and ceiling, illustrated in Fig. 10.

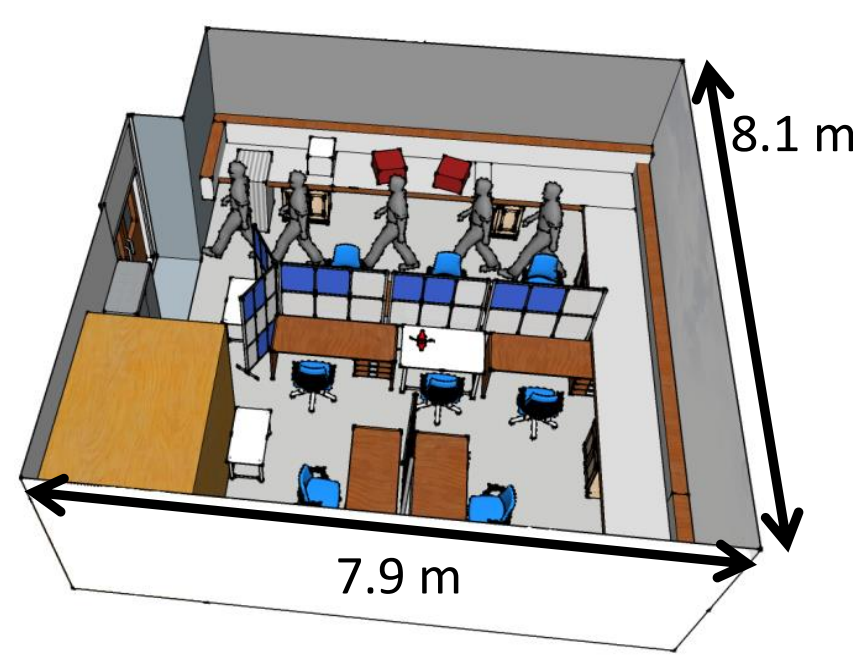

Fig. 10. 3D room layout with partition panels, computer desks, seating and shelving

TABLE V

$\mathrm{S}_{21}$ PeAK VAlue ANd FreQuency FOR DifFERENT ON-Body LocAtions

\begin{tabular}{|l|c|c|c|}
\hline & $\begin{array}{c}\mathbf{S}_{\mathbf{2 1}}(\mathbf{4 3 3} \mathbf{M H z}) \\
{[\mathbf{d B}]}\end{array}$ & $\begin{array}{c}\text { Peak S } \\
{[\mathbf{d B}]}\end{array}$ & $\begin{array}{c}\text { Peak Frequency } \\
{[\mathbf{M H z}]}\end{array}$ \\
\hline Front Head & -42.28 & -41.57 & 436 \\
\hline Left Upper Arm & -46.45 & -38.03 & 452 \\
\hline Right Upper Arm & -43.09 & -36.61 & 448 \\
\hline Upper Left Chest & -46.93 & -45.57 & 438 \\
\hline Upper Right Chest & -46.40 & -45.83 & 426 \\
\hline Upper Front Chest & -44.17 & -42.10 & 440 \\
\hline Cervical Spine & -40.78 & -40.35 & 438 \\
\hline Front Chest & -32.60 & -32.55 & 432 \\
\hline Lumbar Spine & -44.90 & -44.47 & 428 \\
\hline Left Waist & -38.46 & -38.26 & 436 \\
\hline Right Waist & -42.53 & -40.92 & 438 \\
\hline Front Waist & -36.41 & -35.86 & 430 \\
\hline Left Leg & -30.04 & -29.55 & 430 \\
\hline Right Leg & -34.90 & -34.00 & 430 \\
\hline \multicolumn{1}{|c|}{ Maximum } & $\mathbf{- 3 0 . 0 4}$ & $\mathbf{- 2 9 . 5 5}$ & $\mathbf{4 5 2}$ \\
\hline Minimum & $\mathbf{- 4 6 . 9 3}$ & $\mathbf{- 4 5 . 8 3}$ & $\mathbf{4 2 6}$ \\
\hline Average & $\mathbf{- 4 0 . 7 1}$ & $\mathbf{- 3 8 . 9 8}$ & $\mathbf{4 3 6}$ \\
\hline
\end{tabular}


The $S_{21}$ results are summarized in Table V. The range of frequencies for peak $S_{21}$ values was attributed to some body loading on the small antenna, with $433 \mathrm{MHz}$ being the target. The $S_{21}$ for the foot to left leg was the strongest given that it was the shortest distance between the antennas. At $433 \mathrm{MHz}$, the range of $S_{21}$ values was $16.9 \mathrm{~dB}$, which takes account of the channel differences between the Foot-toLeft_Leg and Foot-to-Upper_Left_Chest. The antennas enable links to the footwear from the various body areas with an $S_{21} \geq-47 \mathrm{~dB}$. Comparative measurements in a more open, less-reflective indoor environment showed similar performance.

\section{Antenna performance for mobile subject}

Performance of the footwear-embedded antenna was also investigated for a mobile subject walking in the laboratory, illustrated in Fig. 10. As a subject walks, the foot stride sequence is characterized by six phases: Heel Strike, Flat Foot, Mid-Stance, Heel-Off, Toe-Off and Mid-Swing. On left-foot toe-off, the left arm is forward of the body and can shadow between the trailing foot and the front of the body. To extend the analysis from the immobile case, the mobile $\mathrm{S}_{21}$ measurements were performed at $433 \mathrm{MHz}$ for the footwear to left waist configuration.

$\mathrm{S}_{21}$ values at $433 \mathrm{MHz}$ were recorded continuously for the subject walking back and forth repeatedly for a 60 second period. The subject turned $180^{\circ}$ to reverse direction every 5 seconds and each sample taken every 0.1 seconds. 640 measurements were obtained for each experiment. This was repeated 5 times to establish how consistent the setup was. The results of one set of measurements are shown in Fig. 11 as a function of time.

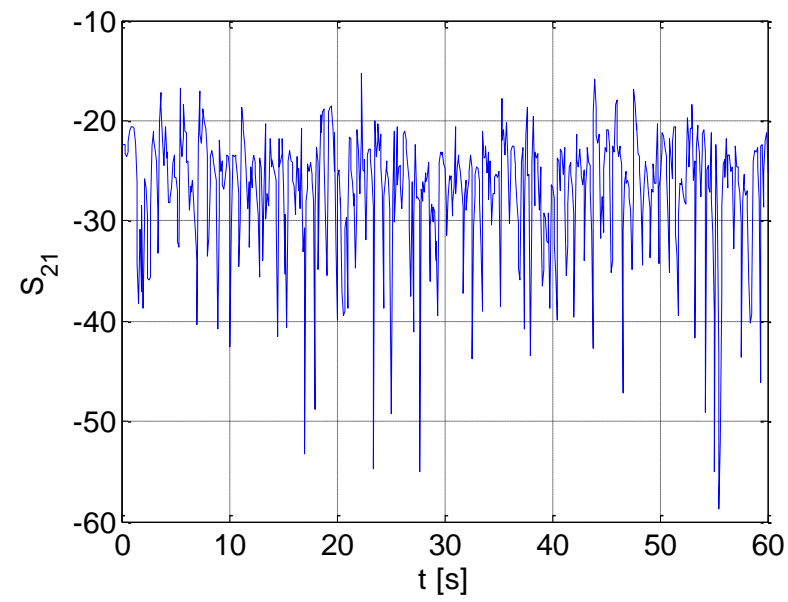

Fig. 11. Measured $S_{21}$ walking subject

While walking, the proximity of the footwear antenna to the reinforced concrete ground varied naturally with foot lift. Similarly, the alignment of the probe antenna varied slightly with the body movement. The $\mathrm{S}_{21}$ did not change significantly when the subject turned direction every 5 seconds. Similar to the immobile case, the signal strength variation was limited and complied with the IEEE 802.15.6 2012 Standard for WBAN [31]. Fading in Fig. 11 was attributed to multipath interference but limited by the short distances between on-body antennas. Fourier analysis of the data sets indicted that the forward arm-swing shadow contributed to some signal delay as the foot lifted (toe-off) from behind the subject.
The distribution of the path loss of each set of measurements was compared with the Rician, Nakagami and Rayleigh distribution using the maximum likelihood criteria. The distribution parameters are summarized in Table VI.

The Nakagami $\mu$ parameter and the Rician $K$ factor indicated a high multipath environment. The low Nakagami $\Omega$ value indicated a small spread for each set of measurements. The Rayleigh distribution was a good fit to each of the measurements, with a constant scaling factor.

TABLE VI

CUMULATIVE DISTRIBUTION FUNCTION OF MEASURED PATH LINKS

\begin{tabular}{|l|c|r|r|r|r|r|}
\hline \multicolumn{2}{|c|}{ Measurement: } & \multicolumn{1}{c|}{$\mathbf{c}$} & \multicolumn{1}{c|}{$\boldsymbol{2}$} & \multicolumn{1}{c|}{$\mathbf{3}$} & \multicolumn{1}{c|}{$\boldsymbol{1}$} & \multicolumn{1}{c|}{$\mathbf{1}$} \\
\hline Rician & $\boldsymbol{K}[\mathrm{dB}]$ & -1.0 & -20.0 & 0.56 & -24.0 & -2.0 \\
\hline \multirow{3}{*}{ Nakagami } & $\boldsymbol{\mu}$ & 1.03 & 0.9 & 1.13 & 0.76 & 1.01 \\
\cline { 2 - 7 } & $\boldsymbol{\Omega}$ & 0.005 & 0.003 & 0.003 & 0.004 & 0.004 \\
\hline Rayleigh & $\boldsymbol{b}$ & 0.05 & 0.04 & 0.04 & 0.04 & 0.04 \\
\hline
\end{tabular}

The cumulative distribution function (CDF) of the 5 sets of measurements of the left waist setup is represented in Fig. 12.

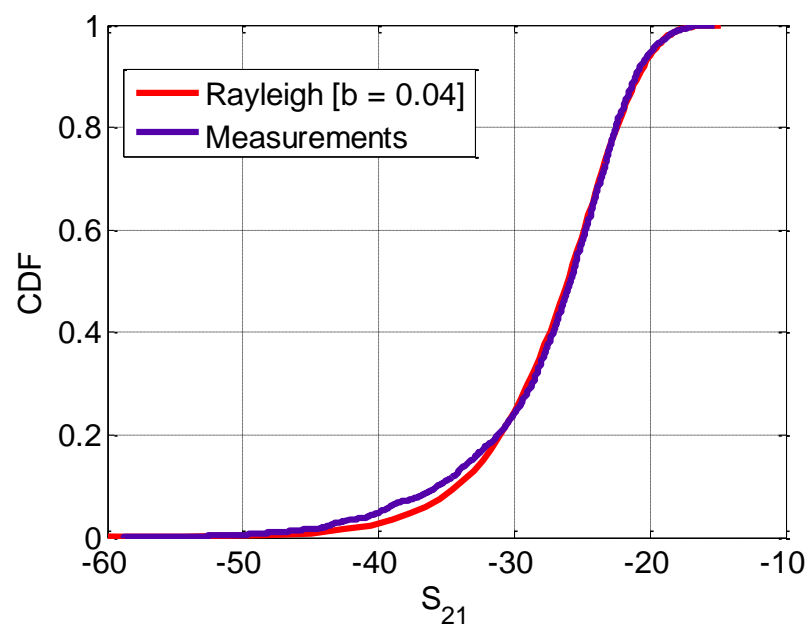

Fig. 12. CDF for 5 measurements of a walking subject with the receiving antenna on the left waist compared to Rayleigh $(b=0.04)$ distribution.

Inspection of the CDF data indicates that $90 \%$ of the observed cases are characterized by an $S_{21}$ greater than $35 \mathrm{~dB}$. The horizontal spread was slightly greater than $44 \mathrm{~dB}$. Considering the IEEE 802.15.6 - 2012 Standard for WBAN, for a data rate of $187.5 \mathrm{Kbps}$, the receiver sensitivity was equal to $-84 \mathrm{dBm}[29]$.

\section{CONCLUSION}

Footwear can accommodate electronic components and antennas that are low-profile and conformal without undue impact on the flexibility of a subject's foot or their natural gait. Integrating biomedical sensors with wireless body area networks necessitates reliable links, particularly in the lower limb area, where the electromagnetic environment can change with rapid leg movements over different ground surfaces.

A large $433 \mathrm{MHz}$ footwear antenna, for improved efficiency at a longer wavelength, was integrated with the insole improved footwear connections with upper body areas. It was designed to radiate from the lateral edges to minimize energy loss in the human foot and body shadowing 
during leg strides. The simulated SAR, for $1 \mathrm{~W}$ equivalent input, was smaller than the limit defined in the standard for all analyzed cases.

Footwear link performances with 14 body areas were initially assessed with a probe antenna at node positions for a static posture. This included upper head to foot links across the body. In all cases, reliable links were demonstrated with $S_{21}$ values greater than $-46.9 \mathrm{~dB}$, which complies with the IEEE 802.15.6 - 2012 Standard on WBAN.

To take account of movement and body shadowing in a realistic office scenario, a measured link between the footwear antenna and a probe antenna on the left waist was studied for a walking subject. The $S_{21}$ measurements were greater than $-58.76 \mathrm{~dB}$, and in $90 \%$ of the cases, greater than $-35 \mathrm{~dB}$.

The $433 \mathrm{MHz}$ footwear antenna was shown to be a viable solution for footwear links with a body area network. Given the good connectivity with multiple upper body areas, it is also suited supporting a body area network hub.

\section{REFERENCES}

[1] Tekscan Systems. (2015, Apr.). F-Scan System: Ultra-thin, inshoe sensors capture timing \& pressure information for foot function \& gait analysis, [Online], Available: http://www.tekscan.com/medical/system-fscan1.html.

[2] I. P. I. Pappas, T. Keller, S. Mangold, M. Popovic, V. Dietz, and M. Morari, "A Reliable Gyroscope-Based Gait-Phase Detection Sensor Embedded in a Shoe Insole," IEEE Sensors J., vol. 4, no. 2, pp. 268-274, Apr. 2004.

[3] H.A. Sabti, D.V. Thiel, "Node Position Effect on Link Reliability for Body Centric Wireless Network Running Applications," IEEE Sensors J., vol. 4, no. 8, pp. 2687-2691, Aug. 2014.

[4] D. Gaetano, V. Sipal, P. McEvoy, M. J. Ammann, C. Brannigan, L. Keating, and F. Horgan, "Footwear-centric body area network with directional UWB antenna," Electron. Lett., vol. 49, no. 14, pp. 860-861, Jul. 2013.

H. M. Schepers, H. F. J. M. Koopman, and P. H. Veltink, "Ambulatory Assessment of Ankle and Foot Dynamics," IEEE Trans. Biomed. Eng., vol. 54, no. 5, pp. 895-902, May 2007.

[6] E. Foxlin, "Pedestrian Tracking with Shoe-Mounted Inertial Sensors," IEEE Comput. Graph. Appl., vol. 25, no. 6, pp. 38-46, 2005.

[7] J. A. Paradiso, S. J. Morris, A. Y. Benbasat, and E. Asmussen, "Interactive therapy with instrumented footwear," in Extended Abastract proc. of the ACM Conferenceo $n$ Human Factors and Comptrting Systems (CHI 2004), 2004, pp. 1341.

[8] M.V. Varnoosfaderani, D.V. Thiel, Junwei Lu, "External Parasitic Elements on Clothing for Improved Performance of Wearable Antennas," IEEE Sensors J., vol. 15, no. 1, pp. 307315, Jan. 2015.

[9] P.B. Samal, P.J. Soh, G.A.E. Vandenbosch, "UWB All-Textile Antenna with Full Ground Plane for Off-Body WBAN Communications," IEEE Trans. Antennas Propag., vol. 62, no. 1, pp. 102-108, Jan. 2014.

[10] D. Gaetano, P. McEvoy, M. J. Ammann, J. E. Browne, L. Keating, and F. Horgan, "Footwear Antennas for Body Area Telemetry," IEEE Trans. Antennas Propag., vol. 61, no. 10, pp. 4908-4916, 2013.

[11] D. Gaetano, P. McEvoy, M. J. Ammann, C. Brannigan, L. Keating, and F. Horgan, "On-body Fidelity Factor for Footwear Antennas Over Different Ground Materials," Eur. Conf. Antennas Propag. (EUCAP), pp.1410-1414, 6-11 Apr. 2014.

[12] C. Prest, S. Wang, and J. Zavala, "Antennas for Compact Portable Wireless Devices,” US Pat. 7,623,077, 2009.

[13] G. Orecchini, M. M. Tentzeris, and L. Roselli, "'Smart Shoe': An autonomous inkjet-printed RFID system scavenging walking energy," Antennas Propag. Soc. Int. Symp., pp. 1417-1420, Jul. 2011.

[14] C. Mariotti, V. Lakafosis, M. M. Tentzeris, and L. Roselli, "An IPv6-enabled Wireless Shoe-Mounted Platform for Health- monitoring," IEEE Topical Conf. Wireless Sensors and Sensor Networks (WiSNet), 2013, pp. 46-48, 20-23 Jan. 2013.

[15] M. Farooqui and A. Shamim, "Dual Band Inkjet Printed Bow-Tie Slot Antenna on Leather," Eur. Conf. Antennas Propag. (EUCAP), pp. 3287-3290, 8-12 Apr. 2013.

[16] D. Gaetano, P. Mcevoy, M. J. Ammann, C. Brannigan, L. Keating, and F. Horgan, "Footwear and Wrist Communication Links Using 2.4 GHz and UWB Antennas," Electronics, vol. 3, no. 2, pp. 339-350, 2014.

[17] M. Kim, J. Takada, and S. Member, "Characterization of Wireless On-Body Channel Under Specific Action Scenarios at Sub-GHz Bands," IEEE Trans. Antennas Propag., vol. 60 , no. 11, pp. 5364-5372, 2012.

[18] A. Sabban, "New Wideband Printed Antennas for Medical Applications," IEEE Trans. Antennas Propag., vol. 61, no. 1, pp. 84-91, 2013.

[19] M. M. Paulides, J. F. Bakker, N. Chavannes, and G. C. Van Rhoon, "A patch antenna design for application in a phased-array head and neck hyperthermia applicator.," IEEE Trans. Biomed. Eng., vol. 54, no. 11, pp. 2057-2063, Nov. 2007.

[20] T. Kumagai, K. Saito, M. Takahashi, and K. Ito, "Design of receiving antenna for microwave power transmission to capsular endoscope," in IEEE MTT-S International Microwave Workshop Series on Innovative Wireless Power Transmission: Technologies, Systems, and Applications (IMWS), 2011, pp. $145-148$.

[21] M. D. Weiss, J. L. Smith, and J. Bach, "RF coupling in a 433 MHz biotelemetry system for an artificial hip," IEEE Antennas Wireless Propa. Lett., vol. 8, pp. 916-919, 2009.

[22] Kiseok Song, Long Yan, Seulki Lee, J. Yoo, and Hoi-Jun Yoo, "A wirelessly powered electro-acupuncture based on adaptive pulsewidth monophase stimulation.," IEEE Trans. Biomed. Circuits Syst., vol. 5, no. 2, pp. 138-146, Apr. 2011.

[23] P. S. Hall, H. Yang, Y. I. Nechayev, A. Alomainy, C. C Constantinou, C. Parini, M. R. Kamarudin, T. Z. Salim, D. T. M. Hee, R. Dubrovka, A. S. Owadally, W. Song, A. Serra, P. Nepa, M. Gallo, and M. Bozzetti, "Antennas and propagation for onbody communication systems," IEEE Trans. Antennas Propag., vol. 49 , no. 3, pp. 41-58, 2007.

[24] S. Gabriel, R. W. Lau, and C. Gabriel, "The dielectric properties of biological tissues: III. Parametric models for the dielectric spectrum of tissues," Phys. Med. Biol., vol. 41, pp. 2271-2293, 1996.

[25] C. A. Balanis, "Linear Wire Antennas - Ground Effects," Antenna Theory: Analysis and Design, 3rd ed., New York, NY, USA, 2005, p. 206.

[26] R. A. Dalke, C. L. Holloway, P. McKenna, M. Johansson and A. S. Ali, "Effects of Reinforced Concrete Structures on RF Communications," IEEE Trans. Electromagn. Compat., vol. 42, no. 4, pp. 486-496, 2000.

[27] International Commission on Non-Ionizing Radiation Protection (ICNIRP), "Guidelines for Limiting Exposure to Time-Varying Electric, Magnetic and Electromagnetic Fields (up to $300 \mathrm{Ghz}$ )", Health Physics, vol. 74, no. 4, pp. 494-522, 1998.

[28] IEEE Standard for Safety Levels with Respect to Human Exposure to Radio Frequency Electromagnetic Fields, $3 \mathrm{kHz}$ to $300 \mathrm{GHz}$, IEEE Standard C95.1 ${ }^{\mathrm{TM}}, 2005$

[29] G. A. Conway and W. G. Scanlon, "Antennas for Over-BodySurface at $2.45 \mathrm{GHz}$," IEEE Trans. Antennas Propag., vol. 57, no. 4, pp. 844-855, 2009.

[30] N. Chahat, M. Zhadobov, R. Sauleau, and K. Ito, "A compact UWB antenna for on-body applications," IEEE Trans. Antennas Propag., vol. 59, no. 4, pp. 1123-1131, 2011.

[31] IEEE Standard for Local and Metropolitan Area Networks-Part 15.6: Wireless Body Area Networks, IEEE Standard 802.15.6, 2012 . 


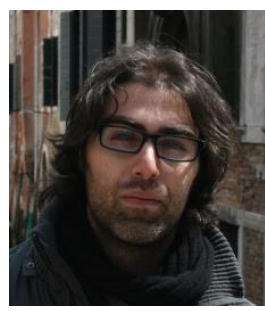

Domenico Gaetano (S'13) received the bachelor's degree in electronic engineering (with an internship in Universitat Autonoma de Barcelona, Spain) in September 2006 and master degree in telecommunication engineering (with an internship in Tyndall National Institute, Ireland), in July 2009 from the University of Calabria, Italy. He received his Ph.D. degree in antenna engineer from the Dublin Institute of Technology, Dublin in 2014. He is currently working as Antenna Engineer in ELT Elettronica S.p.A. in Italy. His research interests include ultrawideband communications, body area wireless communications, and wireless telemetry for physiotherapy and sporting applications.

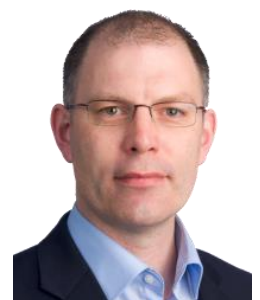

Patrick McEvoy (M'02-SM'14) received the diploma in telecommunications and electronic engineering from the Dublin Institute of Technology, Dublin, Ireland, in 1995, the M.Eng. degree in electronic communications engineering from the University of Hull, Hull, U.K. (with studies at L'Institut Supérieur d'Electronique de Paris, France), in 1998, and the Ph.D. degree in microwave antenna engineering from Loughborough University, Leicestershire, U.K., in 2007. Currently, he is a Senior Researcher at the Antenna and High Frequency Research Centre, Dublin Institute of Technology (DIT). Prior to joining the DIT, he was a Research Manager at the Centre for Mobile Communications Research, Loughborough University, where he worked on switched antennas for handheld terminals, applications of metamaterials, low specific absorption rate antenna design, and antenna measurement systems.

$\mathrm{He}$ has 17 years of applied academic research and industrial experience that includes design, high-volume manufacturing, and measurement systems for miniaturized microwave antennas. His main research interests include the electromagnetic interaction antenna-human tissue, hyperthermia applicators, microwave imaging, body area communications, ultrawideband antennas for frequency and time-domain applications, and the integration of antennas with solar voltaic devices. He has published 80+ scientific papers and has helped to organize four international conferences on antennas and propagation. Dr. McEvoy is a co-recipient of two awards for industrial commercialization of researched antenna technologies and the 2014 Computer Simulation Technology University Publication Award.

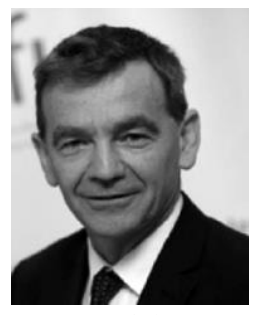

Max Ammann (M'96-SM'08) received the Council of Engineering Institution Part II degree in 1980 and the Ph.D. degree in microwave antenna design from Trinity College, University of Dublin, Ireland in 1997.

He is Assistant Head, School of Electrical and Electronic Engineering, Dublin Institute of Technology (DIT), where he is also the Director of the Antenna and High Frequency Research Centre. $\mathrm{He}$ spent eight years on radio systems engineering and antenna design for TCL/Philips Radio Communications Systems, Dublin, where he commissioned the Nationwide Communications Network for an Garda Siochana. In 1986 he joined the DIT as a Lecturer and was promoted to Senior Lecturer in 2003 and honorary professor in 2012. His research interests broadly include electromagnetic theory, antenna miniaturization for terminal and ultra wideband applications, antennas for medical devices and the integration with photovoltaic systems. He has in excess of 200 peer-reviewed papers published in journals and international conferences.

Dr. Ammann's team received various best paper awards at international conferences on Antennas and Propagation and several commercialization awards. They were also recipients of CST University Publication Awards in 2008, 2011 and 2014. He sits on the management committee of the EU COST Action IC1102, "Versatile, Integrated, and Signal-aware Technologies for Antennas (VISTA)" and is a member of the EurAAP working group on Small Antennas. As a member of the IEEE International Committee for Electromagnetic Safety, he participated in the revision of the IEEE Std. C95.1, 2005 standard for Safety Levels with Respect to Human Exposure to Radio Frequency Electromagnetic Fields, $3 \mathrm{kHz}$ to $300 \mathrm{GHz}$. He has chaired and organized special sessions on small antennas, UWB antennas and UWB Wireless Communication Systems at EuCAP and IEEE APS \& VTC. He was the local chair for the October 2008 EU COST IC0603 workshop and meeting in Dublin. He is currently associate editor for the IEEE Antennas \& Wireless Propagation Letters.

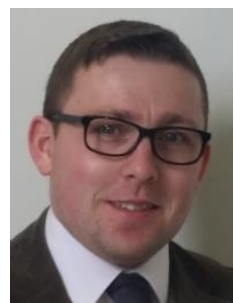

Colm Brannigan graduated from Coventry University, UK, with a BSc (Hons) degree in physiotherapy in 2009. In 2012, he graduated with an MSc degree in advanced physiotherapy from University College Dublin, Dublin, Ireland and in 2014, he graduated with an MSc (Research) degree from the School of Physiotherapy in the Royal College of Surgeons Ireland. His thesis examined, "The effect of a novel footwear telemetry antenna system on the spatiotemporal characteristics of gait and running". Mr Brannigan is a member of the Irish Society of Chartered Physiotherapists (ISCP) and clinical interest groups such as the Chartered Physiotherapists in Musculoskeletal Therapy (CPMT) and Chartered Physiotherapists in Sports and Exercise Medicine (CPSEM).

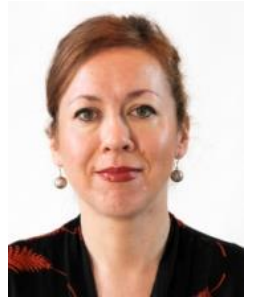

Louise Keating is a graduate of the University College Dublin, Dublin, Ireland, and received the B.Physiotherapy (Hons.) degree and MPhytySt (Manipulative) degree from the University of Queensland, Australia. She is a Lecturer in Physiotherapy at the Royal College of Surgeons in Ireland (RCSI), Dublin and she also contributes to musculoskeletal MSc programmes in University College Dublin. Her research interests include assessment and management of spinal pain and, more recently, the effectiveness and impact of in-shoe orthotics in sports. She is also a Clinical Specialist in Musculoskeletal Physiotherapy and is a committee member of the Chartered Physiotherapists in Sports and Exercise Medicine, a clinical interest group of the Irish Society of Chartered Physiotherapists (ISCP)

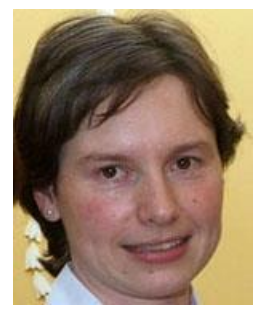

Frances Horgan received the B.Sc. (Hons.), M.Sc. (Research), Diploma in Statistics, and Ph.D. degrees from the University of Dublin Trinity College (TCD), Dublin, Ireland. She is a Senior Lecturer at the School of Physiotherapy, Royal College of Surgeons in Ireland (RCSI), Dublin. Her research interests are care of the elderly, balance, instability, and the impact of footwear on balance, falls, and stroke rehabilitation. She has been conducting research on footwear and falls risk factors in two large Dublin teaching hospitals for several years. These projects have focused on the impact of different types of footwear on balance, footwear, ankle, and foot problems as risk factors for falling. She has grant funding and publications in stroke and elderly rehabilitation. Dr. Horgan is a member of the Irish Society of Chartered Physiotherapists (ISCP), the Irish Society of Chartered Physiotherapists in Neurology and Gerontology, and the Irish Gerontological Society.

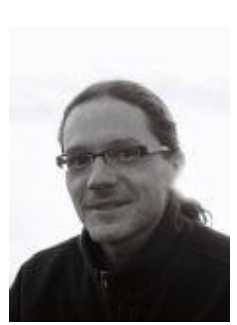

Matthias John (M '07) received the degree (Dipl. Inf.) in computer science from the Deutsche Telekom University of Applied Science, Leipzig, Germany in 2004 and the Ph.D. in Microwave Antenna Engineering from the Dublin Institute of Technology, Dublin, Ireland in 2008.

$\mathrm{He}$ is currently working as a postdoctoral researcher in CTVR - the Telecommunications Research Centre in Trinity College Dublin. His research interests include UWB antennas, efficient numerical optimization techniques, antenna miniaturization, RFID and imaging applications. He is driving commercial activity in the center and received commercialization awards in 2009, 10 and 11 for technologies licensed to Irish and international companies. He also received a 2011 CST Award for work on "Miniature Ceramic Dual-PIFA Antenna to Support Band Group 1 UWB Functionality in Mobile Handset". He is funded by Science Foundation Ireland. 